Article

\title{
Large-Scale, Multi-Temporal Remote Sensing of Palaeo-River Networks: A Case Study from Northwest India and its Implications for the Indus Civilisation
}

\author{
Hector A. Orengo ${ }^{1, *}$ (D) and Cameron A. Petrie ${ }^{2}$ \\ 1 McDonald Institute for Archaeological Research, University of Cambridge, Downing Street, \\ Cambridge CB2 3ER, UK \\ 2 Department of Archaeology and Anthropology, University of Cambridge, Downing Street, \\ Cambridge CB2 3DZ, UK; cap59@cam.ac.uk \\ * Correspondence: hao23@cam.ac.uk
}

Academic Editors: Nicola Masini and Prasad S. Thenkabail

Received: 6 June 2017; Accepted: 12 July 2017; Published: 16 July 2017

\begin{abstract}
Remote sensing has considerable potential to contribute to the identification and reconstruction of lost hydrological systems and networks. Remote sensing-based reconstructions of palaeo-river networks have commonly employed single or limited time-span imagery, which limits their capacity to identify features in complex and varied landscape contexts. This paper presents a seasonal multi-temporal approach to the detection of palaeo-rivers over large areas based on long-term vegetation dynamics and spectral decomposition techniques. Twenty-eight years of Landsat 5 data, a total of 1711 multi-spectral images, have been bulk processed using Google Earth Engine $^{\odot}$ Code Editor and cloud computing infrastructure. The use of multi-temporal data has allowed us to overcome seasonal cultivation patterns and long-term visibility issues related to recent crop selection, extensive irrigation and land-use patterns. The application of this approach on the Sutlej-Yamuna interfluve (northwest India), a core area for the Bronze Age Indus Civilisation, has enabled the reconstruction of an unsuspectedly complex palaeo-river network comprising more than $8000 \mathrm{~km}$ of palaeo-channels. It has also enabled the definition of the morphology of these relict courses, which provides insights into the environmental conditions in which they operated. These new data will contribute to a better understanding of the settlement distribution and environmental settings in which this, often considered riverine, civilisation operated.
\end{abstract}

Keywords: multi-temporal; seasonal; vegetation; palaeo-river; Indus Civilisation; archaeology

\section{Introduction}

Remote sensing and multi-spectral imagery have considerable potential for the detection of changing river systems and the reconstruction of hydrological networks, particularly those that are no longer easily visible on the ground. Such approaches have been applied to detect relict water courses, palaeo-channels and palaeo-rivers in various regions and environments across the world (e.g., [1-8]). Remote sensing approaches to palaeo-hydrology and ancient irrigation display a long tradition and have been particularly fruitful in Mesopotamia and other riverine and channel-dependant ancient civilisations. However, most studies have employed single data sources or images acquired at one point in time. While single or limited time-span imagery are a rich source of data, they are unlikely to document annual or long-term variation in sub-surface moisture content and surface vegetation, which are key factors in the detection of palaeo-hydrology $[1,8,9]$. 
The promulgation of a wide variety of declassified and low- or no-cost remotely sensed imagery means that a considerable quantity of multi-spectral imagery is now widely available, and this corpus clearly constitutes Big Data. The ability to use such large and abundant imagery datasets to their fullest effect is limited, however, by storage capacity and computational power. This paper presents a novel approach to processing big data imagery datasets to detect palaeo-rivers and reconstruct hydrological networks in a specific case-study region in northwest India, which is characterised by both annual and long-term variation in water availability and environmental conditions. The terms palaeo-river and palaeo-channel are used interchangeably to denote a remnant of an inactive river or channel in which the riverbed is filled with sedimentary deposits.

\section{Project Background}

The plains of northwest India, which include parts of the states of Punjab, Haryana, and northern Rajasthan, are often referred to as the Yamuna-Sutlej interfluve (Figure 1), as they stretch between the Yamuna and Ganges hydrological system to the east and the Sutlej to the west, which is the easternmost river of Punjab, and part of the greater Indus hydrological system. The flat physiography of the plains of the Indus, Punjab and Yamuna-Sutlej interfluve, in conjunction with their proximity to the Himalayas, and the distribution of winter rain and summer monsoon rain combine to produce a distinctive environmental zone, where water availability is extremely seasonal, has significant variability, and can produce very active fluvial processes [10]. This variability had the potential to have had dramatic consequences for early settlers of the region. Often described as being riverine (e.g., [11]), the Indus Civilisation is characterised by a relatively small number of large urban nuclei (e.g., Harappa, Mohenjo-Daro) and an abundance of smaller town and village settlements, which are distributed across the Indus River watershed and its surrounding regions in both modern Pakistan and India. These settlements occur in a wide range of environments, and while a number appear to lie close to watercourses, a significant proportion seem not to have had direct access to perennial water $[10,12]$. Despite this, there has been considerable historical interest in the hydrology of this region and the plains of northwest South Asia in general, which has been markedly focused on the believed proximity between Indus settlements and relict watercourses (e.g., [13-21]).

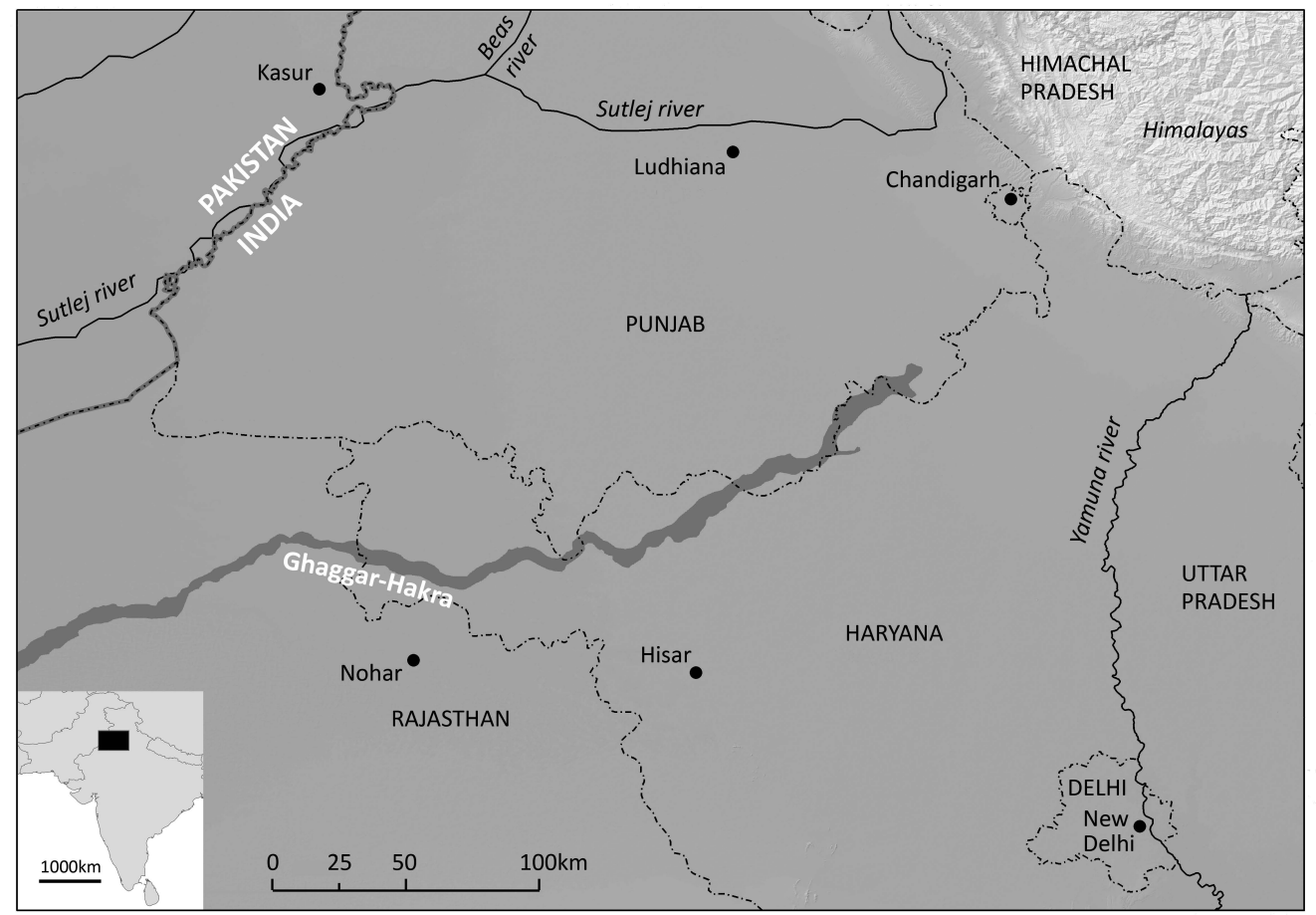

Figure 1. Location of the study area. 
Since the 1980s, satellite images have been employed to trace dry riverbeds and reconstruct the ancient hydrological system in the region [22]. Although these studies have successfully identified multiple palaeo-rivers, they have typically relied on visual interpretation of RGB composites of single multispectral or mosaicked images (mostly Landsat 5-7 multispectral imagery) with visibility being determined by the particular environmental conditions at the moment that the image was acquired. These approaches have largely focussed on the detection of the ancient riverbed of the Ghaggar-Hakra (often identified as the Sarasvati River, which is the only river mentioned in the ancient Vedic texts that does not correspond to any current watercourse) and its most readily visible relic tributaries. While such an approach might be valid for the detection of large palaeo-rivers within a single environmental zone, it only provides limited information on the characteristics of the hydrological system that maintained that river. The reconstruction of as much as possible of a hydrological network is an essential factor to understanding the character and historical morpho-dynamics of any particular river. Environmental changes that could have originated well beyond the visible trace of a riverbed have the potential to affect changing water flow and sediment load, which are both important factors that could affect the river's morphology, course, and bring about its eventual disappearance.

In South Asia, the focus on particular large rivers instead of entire networks might be due to the strong attention given to the relationship between palaeo-channels and the distribution of known archaeological sites, particularly those related to the Indus Civilisation [23-27]. Though not often emphasised, these plains also have evidence for significant occupation in the Early Historic and later periods [28,29], which will also have been affected by hydrological change. In many instances, ancient sites have been used to verify the results of remote sensing or RS-based analysis, and also to construct a chronological framework for the ancient watercourses (e.g., [24,25,30] (pp. 359-384), and [31]), which creates an inherent circularity.

The study area is centred on the Sutlej-Yamuna interfluve (Figure 1) or the Haryana-Punjab plain, which includes parts of the modern provinces of Haryana, Punjab and Rajasthan in India, and covers an area of approximately $80,000 \mathrm{~km}^{2}$. This greater region includes a high diversity of environments, ranging from channel irrigated agricultural areas in the north to the Thar Desert of northern Rajasthan to the south. In geomorphological terms, the area displays a remarkably flat surface with a height difference of $100 \mathrm{~m}$ in over $300 \mathrm{~km}$ of distance. This plain is comprised of quaternary alluvial deposits originating from the Himalayas [26].

This paper has two interrelated research objectives. Firstly, it sets out to demonstrate a robust method for carrying out accurate hydrological modelling of an area with very complex hydrology using large multi-temporal data sets. The second research objective is specifically archaeological. Building upon the work carried out in northwest India by the Land, Water and Settlement project [10], an ERC-funded project entitled "Winter Rain, Summer Rain: Adaptation, Climate Change, Resilience and the Indus Civilisation (TwoRains)" is exploring the mechanisms involved in the human adaptation to, and management of, variable and changing water availability. In this regard, the reconstruction of the whole palaeo-hydrological network of northwest India will be instrumental to model and test hypotheses on water movement, accumulation, seasonality, and availability in relation to changing climate and rainfall patterns. This paper discusses the first results of an investigation in this direction.

\section{Materials and Methods}

There have been many previous attempts to detect the palaeo-rivers in northwest India using satellite imagery (e.g., [22,32-40]). However, previous RS research has not typically incorporated the whole of the Sutlej-Yamuna interfluve and in the cases where comprehensive RS has been carried out, studies have usually employed single data sources (e.g., Landsat 5-7 multispectral satellite imagery) or several images acquired during the same period, mosaicked over the specific area of interest of each study. These are logical approaches as the reconstruction of the palaeo-hydrological network of a very large area such as the Yamuna-Sutlej interfluve would have been limited until recently to what could 
be attempted due to limitations in computational power and data availability. In addition, this region poses particularly challenging detection problems.

Firstly, the Sutlej-Yamuna interfluve includes a high diversity of environments, from areas of irrigated cultivation to desert. Such variability complicates the visibility of ancient water-related features, as the factors influencing it such as vegetation, seasonal rain, soil moisture and sediment type would vary in areas with different environmental settings. The use of images from a single sensor acquired during the same period would likely be unable to reflect a significant percentage of the features of interest.

Secondly, the area has been subject to large-scale landscape modifications and significant land-use changes, particularly since the introduction of mechanised agriculture and extensive irrigation. These inter-related innovations have had an enormous effect in the visibility of palaeo-rivers in multispectral imaging, which was already important in the late 1970s as noted by Bakliwal and Sharma [41] (p. 461). Most notably, a large network of irrigation channels (with main distribution branches reaching 50 and $100 \mathrm{~m}$ wide) crosses the interfluve. These channels have a double effect in that they: (1) act as an effective barrier to topographic water movement through natural basins; and (2) distribute water to areas that might have not been watered under natural conditions. This interference in the natural hydrology not only diminishes the capacity of ancient courses to retain moisture and increase their visibility, but it also boosts the detection of false positives in the form of relatively modern linear extensions of watered soils served by individual water channels. The introduction and wider access to mechanised agriculture has also facilitated the systematic flattening of large portions of the study area for agricultural purposes, which is a pre-condition for the distribution of channelled water. Although the physiography of the landscape is very flat, features such as ancient habitation mounds and the levees and channels of ancient rivers provide a certain relief, which could have hindered channelled water distribution. The flattening of the landscape resulted in the filling of small palaeo-channels, decreasing their capacity to retain moisture, but also in a strong reflectance of the artificial water channel network and the irrigated fields, which hinders the more subtle indications of ancient watercourses.

Thirdly, seasonal and long-term cultivation changes prevent a uniform visual analysis of the area, which appears as a constantly changing mosaic of cultivated fields in which visibility of palaeo-rivers is partly dependant of the particular cultivation state of the fields planted on the overlying ground surface. This variability again poses a challenge for the use of a single image or images taken during the same period as, at any given moment, only a small part of the area would provide adequate conditions for the detection of palaeo-rivers.

Taking into account the environmental particularities of the area of interest and aiming to achieve the maximum detection potential, a large-area, multi-sensor and multi-temporal approach was adopted. This approach aimed to provide a means of overcoming environmental variability, land-use changes, seasonal cultivation patterns and extensive landscape modifications as much as possible. Multi-temporal datasets have the capacity of include diverse environmental and land-use scenarios and their seasonal and statistical treatment can highlight those features that would not be visible during a single particular period, area and/or land-use strategy. In order to implement such an approach Google Earth Engine $^{\odot}$ (EE) was employed as a particularly well-adapted tool to achieve the research aims. EE is a web-based geospatial computing platform with several inter-related components. The Code Editor is an integrated development environment for EE's JavaScript application programming interface. It allows users to write and run their own scripts using EE's JavaScript implementation to import, process, analyse, visualise and export satellite imagery. EE's Code Editor was employed to write and execute the scripts (see Supplementary Materials) necessary to perform the analyses described in this paper. More importantly, EE provides two features that are extremely beneficial for big data multi-temporal remote sensing: (1) access to petabytes of satellite imagery, which includes all Landsat series, ASTER, MODIS, Sentinel 1 and 2, SRTM, and other freely available sources; and (2) capacity to run scripts through Google's cloud parallel computing infrastructure. The former is an important 
feature as it allows access to more than 40 years of satellite imagery without the need to query and download the data from publicly available repositories, which would have required hundreds of query and download hours and a large storage space. The latter enables the execution of analytical runs using Google's high-performance computing cluster; which is essential as the extent of the study area together with the multi-temporal approach adopted by this study, and the size of the necessary multispectral dataset is within the realm of Big Data analysis, and well beyond the analytical capabilities of any high-end desktop computer.

\subsection{Seasonal Multi-Temporal Vegetation Indices (SMTVI)}

Preliminary assessment of the study area and the results of previous studies (particularly [22,39,40], but also [36,37]) point to a strong relationship between the visibility of palaeo-rivers and the presence/health of surface vegetation, which in turn is related to water availability. Therefore, it was recognised that the use of different indices for the analysis of vegetation health and water content over long periods of time have the potential to offer important insights into the tracing of palaeo-rivers and channels. In order to explore this relationship, different vegetation indices derived from Landsat 5 imagery were employed. Despite its reduced spectral resolution with respect to later satellites, Landsat 5 was considered the best source to develop this study as it has produced almost 30 years of imagery (from 1984 to 2013), some of it acquired prior to the construction of some of the large water channels in the area. It therefore provides an ideal source for developing long-term multi-temporal imagery analysis. The EE image repository provides NDVI, EVI [42] and NDWI [43] annual, 32 and 8-day composites of Landsat 5 imagery. For the study area, their calculation included 2266 Landsat 5 TM level 1T orthorectified scenes, using the computed TOA reflectance [44] and filtered from cloud cover [45]. These were acquired from 1 January 1984 to 8 May 2012. A script was written (available as Supplementary Materials) to group the 1254 available 8-day EVI composites into single mean two-month images. Each of these was the average of all 8-day EVI composites for the same two months from 1984 to 2012 for the study area. It was decided to select 8-day instead of 32-day composites in order to preserve the temporal integrity of the data as much as possible while the grouping of the vegetation indices into two-month averaged values would allow exploring seasonal variability. Every multiyear bimensal image was the result of averaging around 200 8-day composite images.

The images resulting from the application of the different vegetation indices show similar results, with EVI producing a slightly clearer identification of palaeo-rivers (Figure 2). Seasonality seems to be a much more important factor than the type of vegetation index employed, as the images from January-February, March-April and July-August present a surprisingly clear visibility of palaeo-rivers, which are undetectable in other images (Figure 2). This seasonal difference is probably related to the fact that these months closely correspond to the Indian rainy seasons. Two methods were tested to facilitate the visualisation of the entire palaeo-river network: a RGB composite of the three principal components from a PCA of all bimensal images; and a Seasonal Multi-Temporal Vegetation Index (SMTVI), which resulted from creating a RGB composite of the three EVI images corresponding to the Indian Winter rainy season and Summer Monsoon months (January-February, March-April and July-August). Although most palaeo-rivers were visible in the principal component composite, SMTVI (Figure 3) offered a better visibility, probably related to the reduction in non-relevant information (i.e., months in which palaeo-rivers were not visible).

In order to further explore the seasonal variability of the vegetation indices a normalised difference vegetation seasonality index (NDVSI) was developed using the following calculation:

$$
\frac{((\overline{\mathrm{x}} \mathrm{WNIR}+\overline{\mathrm{x}} \mathrm{WRED}) / \overline{\mathrm{x}} \mathrm{WNIR})-((\overline{\mathrm{x}} \mathrm{DNIR}+\overline{\mathrm{x}} \mathrm{DRED}) / \overline{\mathrm{x}} \mathrm{DNIR})}{((\overline{\mathrm{x}} \mathrm{WNIR}+\overline{\mathrm{x}} \mathrm{WRED}) / \overline{\mathrm{x}} \mathrm{WNIR})+((\overline{\mathrm{x}} \mathrm{DNIR}+\overline{\mathrm{x}} \mathrm{D} R E D) / \overline{\mathrm{x}} \mathrm{DNIR})}
$$

Here, $\bar{x} W$ represents the mean values of $L 5$ images during the rainy seasons and $\bar{x} D$ the mean values of L5 images during dry months. The NDVSI image (Figure 4) provided a good guide on 
the areas where seasonal vegetation variability was at its greatest and, therefore, the use of seasonal vegetation indices had the potential to yield a higher amount of information. An immediate result of the application of the NDVSI was the clear difference between the northern and southern sectors of the study area (Figure 4). While the northern sector has the potential to provide new information based on the seasonal variability of vegetation, the exploration of seasonal variability of vegetation indices could barely produce relevant results in the southern sector. This is probably due the fact that this area has a hotter and dryer climate and is currently dependent on irrigation for crop cultivation.
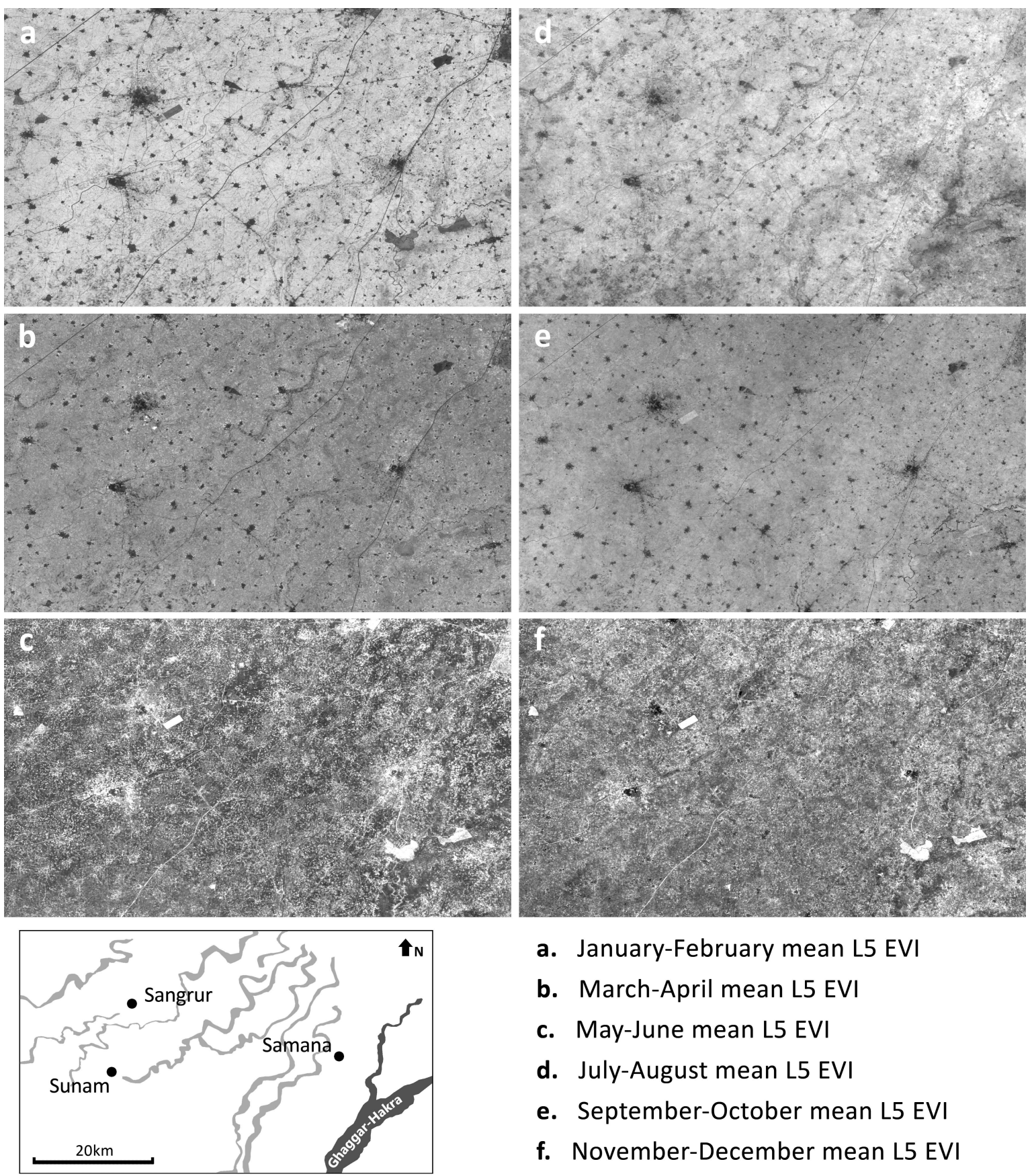

a. January-February mean L5 EVI

b. March-April mean L5 EVI

c. May-June mean L5 EVI

d. July-August mean L5 EVI

e. September-October mean L5 EVI

f. November-December mean L5 EVI

Figure 2. Seasonal variability of bimensal averages of long-term vegetation indices $(\mathbf{a}-\mathbf{f})$. Note the higher visibility of palaeo-rivers in the rainy months: January-April (a,b); and July-August (d). 

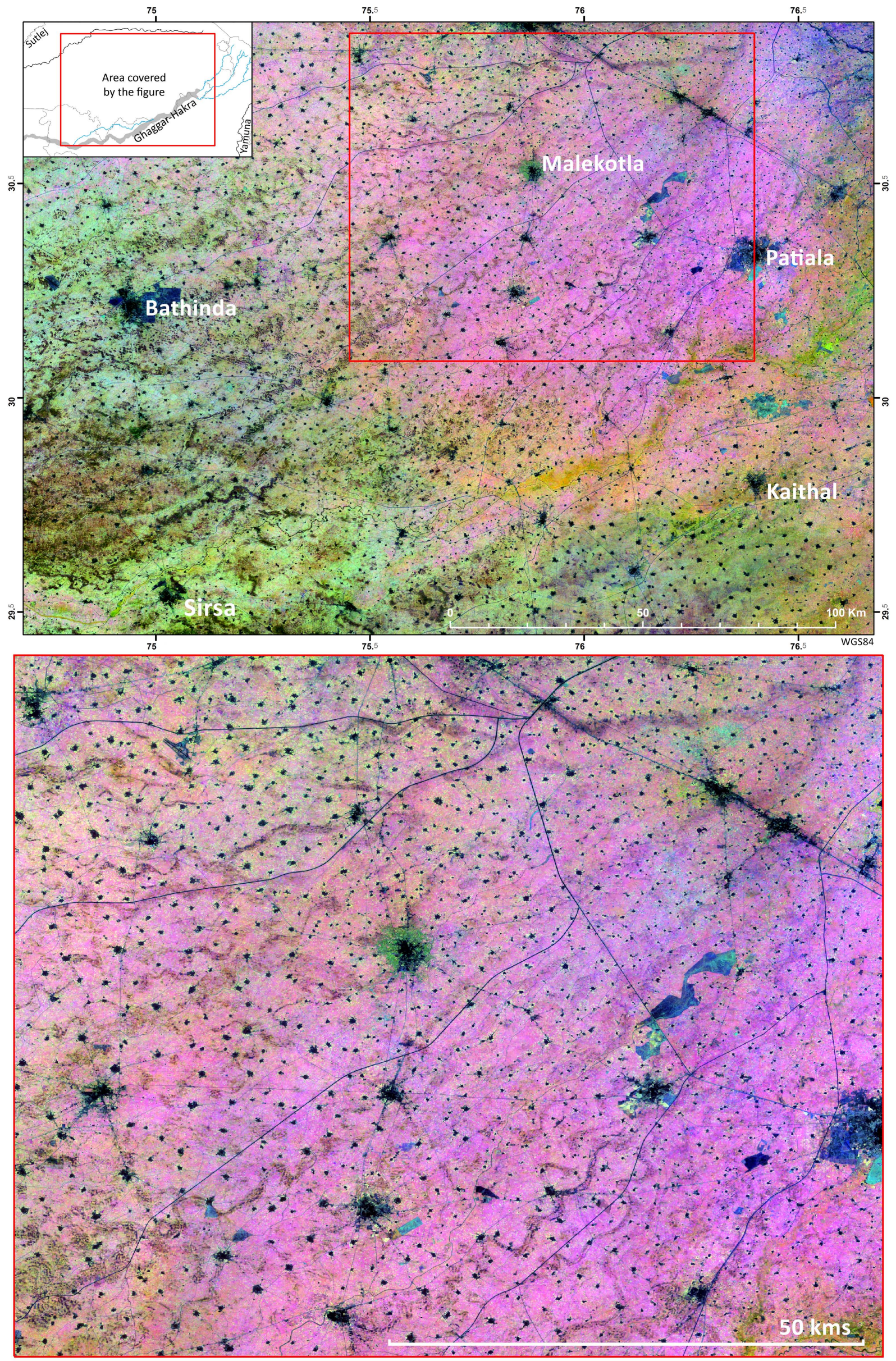

Figure 3. Image resulting of the application of Seasonal Multi-Temporal Vegetation Indices (SMTVI) for the rainy months as an RGB Composite of the 1984-2012 EVI averages (R: July-August; G: Mary-April; and B: January-February). 


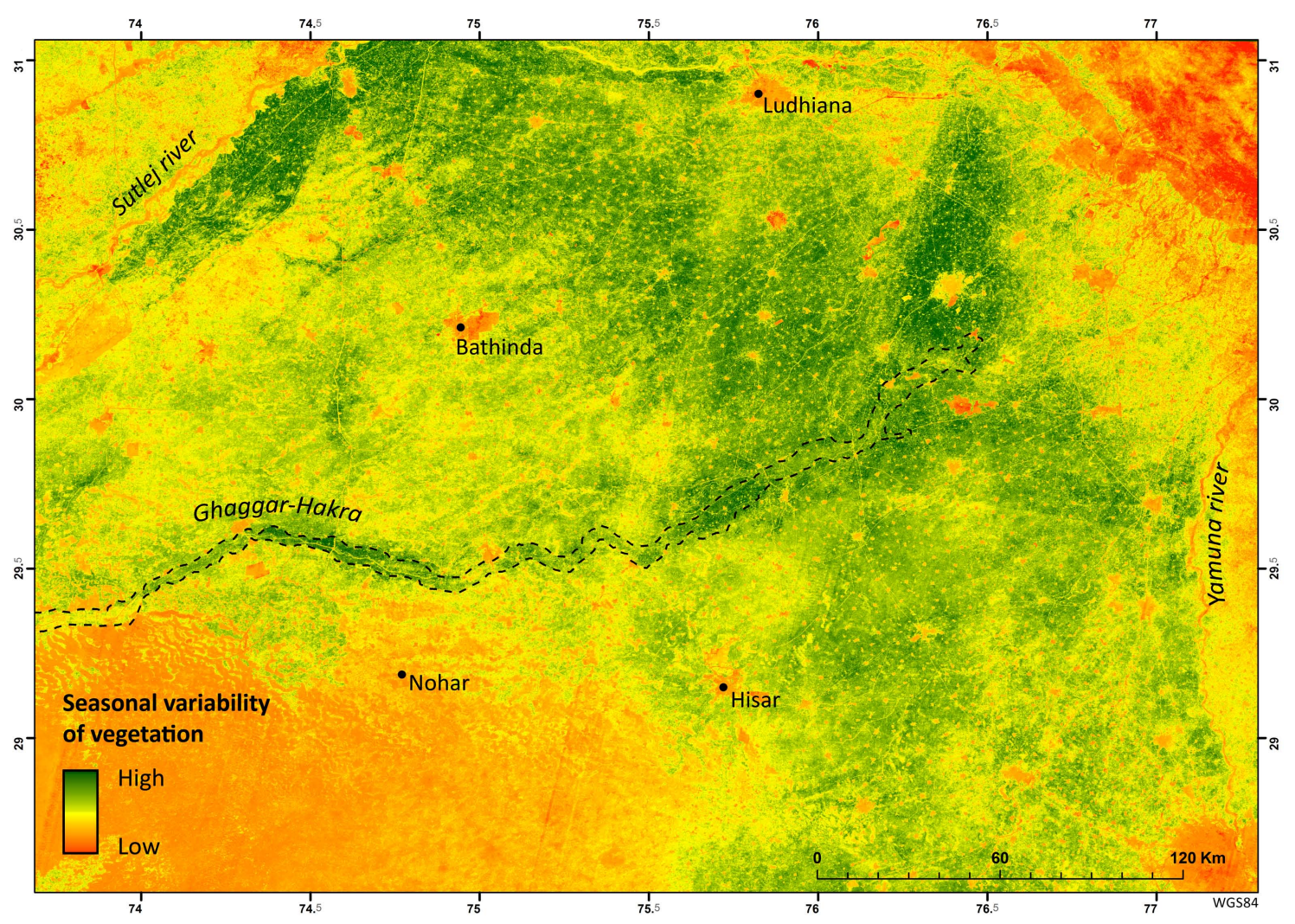

Figure 4. Normalised Difference Vegetation Seasonality Index (NDVSI) of the study area where the greenest areas indicate a higher seasonal variation of vegetation. Ghaggar-Hakra palaeo-channel has been highlighted with a dashed line.

\subsection{Spectral Decomposition Techniques}

Based on the indications provided by the NDVSI, a different approach making use of spectral decomposition techniques, in particular Tasselled Cap Transformation (TCT) and Principal Component Analysis (PCA) of multispectral imagery, was also applied in the study area. These were considered good exploratory techniques as they both reduce the amount of information available in the multispectral datasets to weighted sums of separate channel readings. These techniques effectively reduce data dimensionality facilitating their interpretation. Both TCT [46-48] and PCA were produced using the mean values of all Landsat 5 images available for the study area. In addition to this, and in order to test the seasonal influence in the visibility of palaeo-rivers, TCTs and PCAs were calculated for the mean of images acquired during the Indian winter rain season and summer Monsoons and during the dry months.

The combination of these different approaches was designed to increase the detection of palaeo-rivers and decrease the occurrence of false positives. Figure 5 provides a description of the workflow that was followed. Figure 5 also includes indications on the preferential application of the different techniques following the guide provided by the NDVSI. A detailed account of the results obtained follows. 


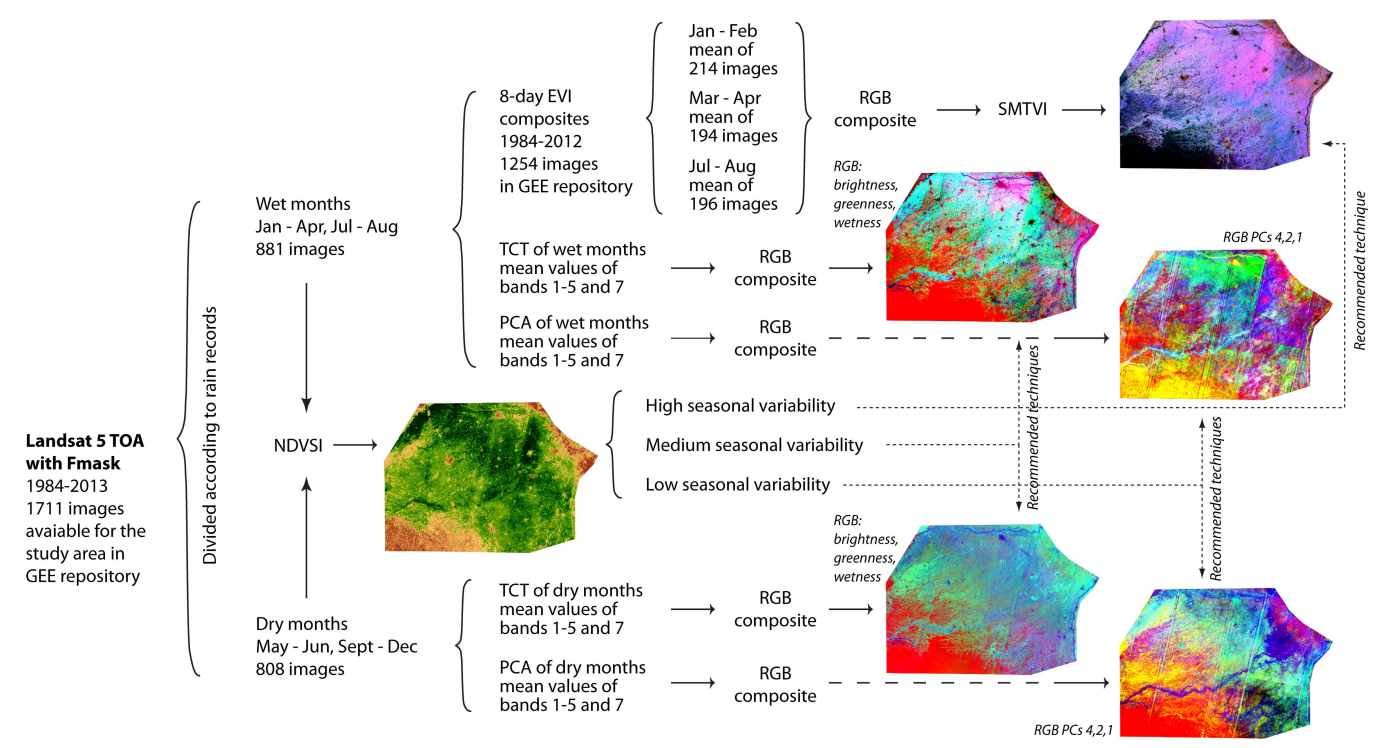

Figure 5. Workflow followed for the generation of the different outputs described in the text and their recommended application according to seasonal vegetation variability.

\section{Results}

A total sum of 8246 kilometres of palaeo-channels was mapped using both SMTVI and spectral decomposition techniques (Figure 6). The palaeo-rivers and channels were delineated by hand using a vector-based GIS desktop platform as testing of edge/line detection algorithms and automatic processing did not provide results that were reliable enough. The resulting map of palaeo-rivers in the area cannot in any way be taken as definitive, as multiple palaeo-rivers may remain undetected. This is particularly true of the southernmost sector of the study area (south of the main Ghaggar-Hakra channel) as defined by the results of the NDVSI analysis (Figure 4). The results of the two methods adopted will now be described and analysed.

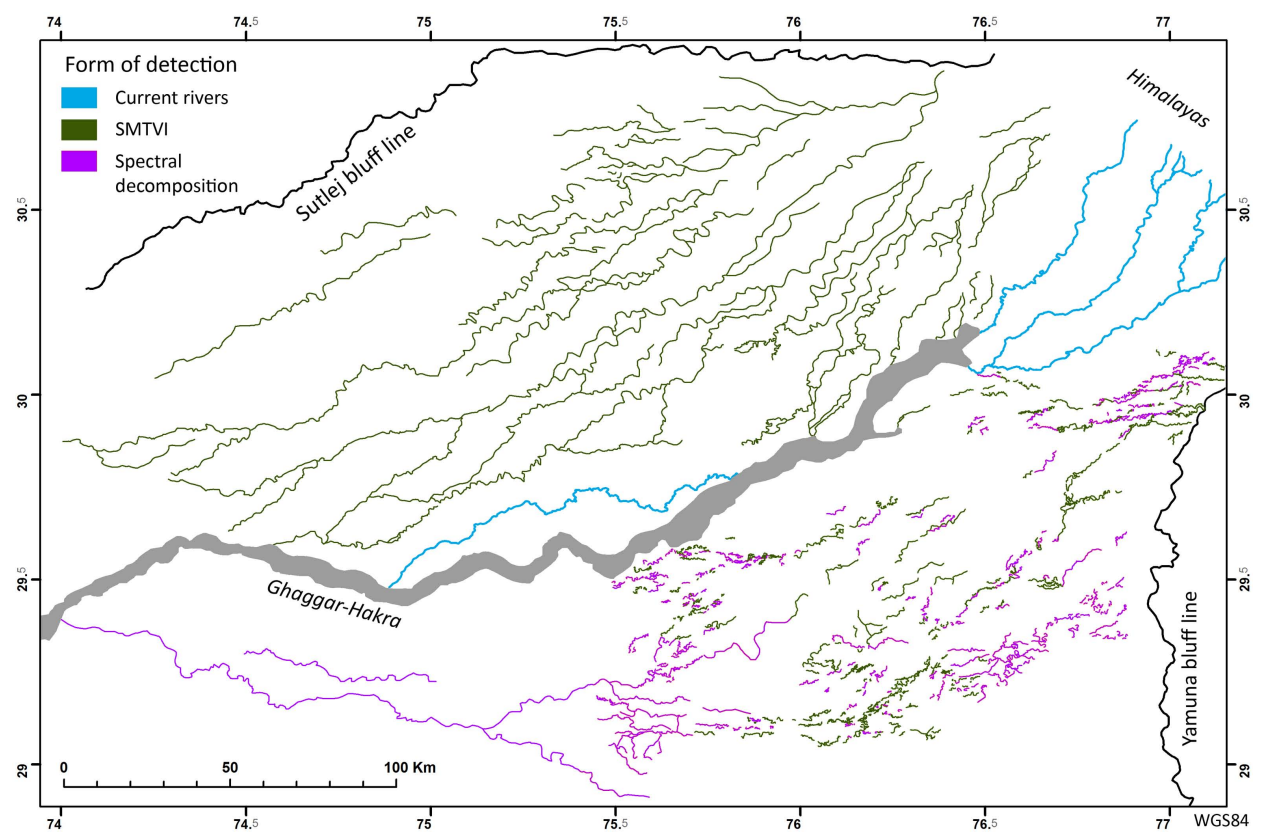

Figure 6. Results of the interpretation of both SMTVI and seasonal multi-temporal spectral decomposition techniques for the reconstruction of the palaeo-hydrological network of the Sutlej-Yamuna interfluve. 


\subsection{SMTVI}

SMTVI resulted in the clear visualisation of a range of formerly reported palaeo-rivers, but also multiple previously undetected ones. This approach only failed to yield results in the southern sector of the area under study, in particular below the main Ghaggar-Hakra channel where dune morphologies dominate the landscape. In this area, the results of the NDVSI analysis (Figure 4) indicate a very low seasonal variability of vegetation.

A total of $5034 \mathrm{~km}$ of palaeo-rivers have been mapped through SMTVI, and these were predominantly in the northern sector of the study area (Figure 6). The results of this technique show that the traces of palaeo-rivers form a more complex network than previously suspected. Previous studies in this area have been successful in detecting a number of these palaeo-rivers (Figure 7). For example, the results obtained by Yashpal et al. [22] and van Dijk et al. [40] are partly coincident with our own even if, in the Yashpal et al. [22] case, some features have been joined to form continuous channels for which we have not found evidence. In several instances, palaeo-rivers detected by these authors seem to be coincident with large modern irrigation channels, which is unsurprising given the early date and small scale at which the analysis was conducted. SMTVI has also been unable to find traces of the old channel of the Sutlej and the old channel of the Yamuna 1, as described by Yashpal et al. [22]. All features detected in the northern sector of the study area by van Dijk et al. [40] have been identified, as have most of those detected in the west sector, but we have also detected many others not documented by van Dijk et al. [40]. Bhadra et al's [39] hypothesised location of palaeo-rivers in the area do not coincide with the results of our study nor with any other previous analyses under consideration. In general, it can be said the SMTVI provided a more consistent approach for the medium resolution detection of palaeo-rivers across a very large area displaying higher values of seasonal vegetation variability.

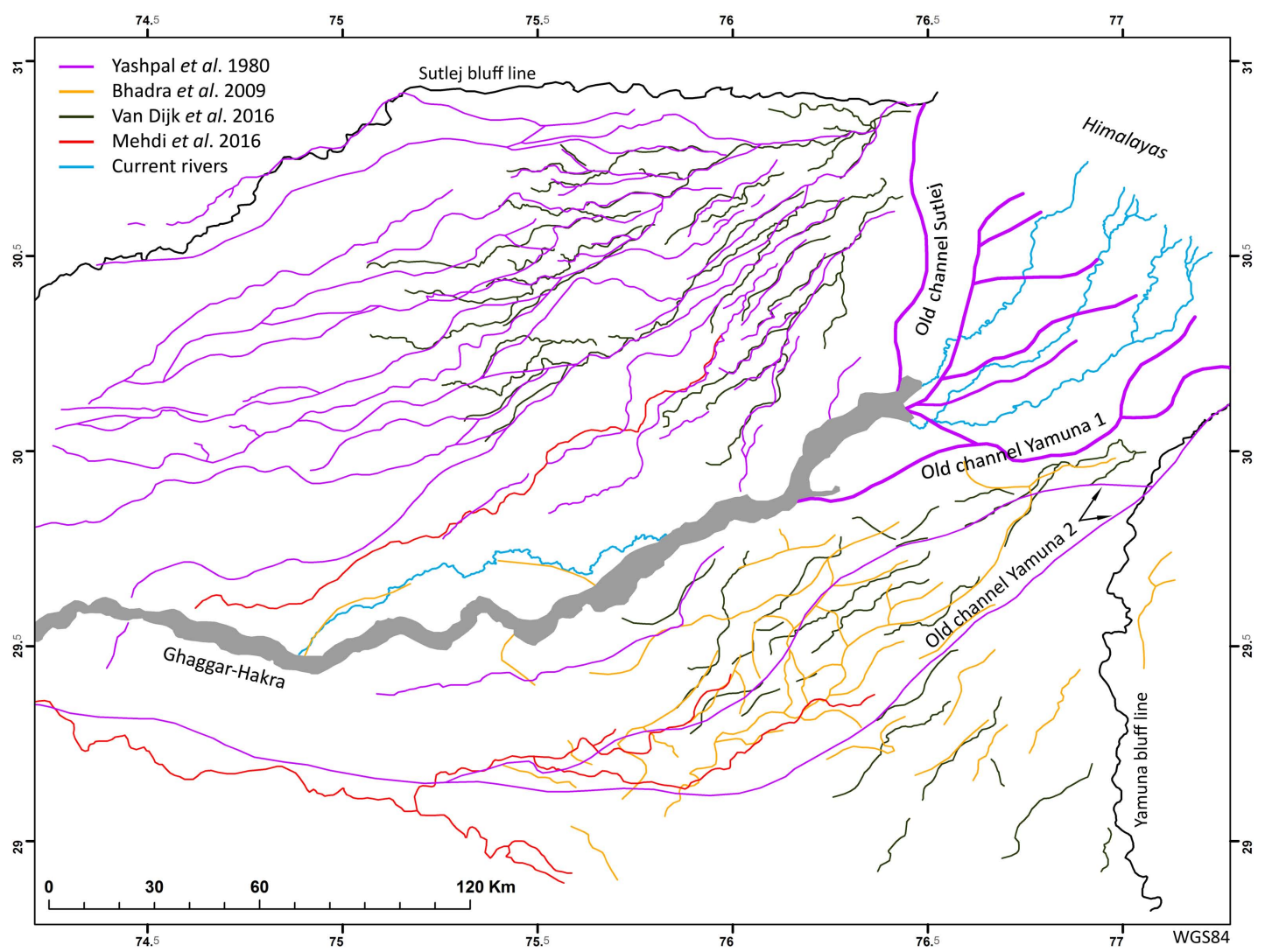

Figure 7. Palaeo-rivers detected in the study area by previous Remote Sensing-based studies. 
The visibility of the palaeo-rivers in SMTVI (Figure 3) is a reflection of the interplay between past fluvial geomorphology and current multi-year vegetation dynamics. In this regard, a more detailed analysis of the characteristics of the detected features can help the understanding of past environmental conditions. Monsoonal rains imply a strong rise of soil moisture and surface vegetation. However, palaeo-rivers in SMTVI are not detected through higher vegetation values but, on the contrary, as linear groupings of low value pixels, that is, as features where the average vegetation values during the last thirty years have been significantly lower than in their surroundings. The very low terrain slope (average of $0.37 \%$ ) and the high volume of rainfall during the winter and summer rain periods, which merge and flow down the foothills of the Himalayas, combine to create a large depositional floodplain. The rivers that have been documented form a parallel drainage pattern and present a highly sinuous and meandering morphology in which multiple meanders and meander scars are visible. The low value pixels that define their trace seem to correspond to two types of features: (1) large natural levees typically formed after multiple flooding episodes [49] - these are usually elevated with respect to the floodplain, as confirmed by SRTM $30 \mathrm{~m}$ data, and accumulate thicker and coarser sediment [50]; and (2) coarser channel deposits and alluvial deposits accumulated in the inside of river bends. Both proximal areas of levees, inner river bends and channel bedload tend to concentrate coarser sediments [51], which might have resulted in less fertile soils with higher water subsurface infiltration and lateral water runoff in the case of the levees. Water would have been concentrated and retained by the finer material and flatter topography present at the backswamp areas of the floodplain, where bright pixels reflect a correlation between seasonal rainfall and healthier vegetation. The contrasting vegetation response between the coarser deposits close to the river channel and their surrounding floodplain account for the clear palaeo-river visibility in this area. The presence of ribbon-like deposits and their attendant levees is consistent with the existence of rivers with a high suspended sediment fraction forming a rapidly aggrading system where avulsive channels are common [51] (p. 6).

Several relevant results for the reconstruction of the hydrologic history of the northern sector of the study area have been obtained through the use of seasonal vegetation mapping: (1) the confirmation of a major palaeo-course of the later Sutlej river, which contributed to the Ghaggar-Hakra system, though when and for how long remains unknown (top right corner of the lower image in Figure 3); (2) the migration of this same major watercourse from the Ghaggar-Hakra catchment to that of the Sutlej, which would have significantly reduced the amount of water available in the Ghaggar-Hakra's lower course; and, perhaps most significantly, (3) the multiplication of the palaeo-rivers known in the area, which indicates that as a whole, the region has an extremely complex fluvial history, which will have had important and as yet poorly resolved consequences for water availability and thus also for past human habitation and land-use. SMTVI also allowed study of the morphology of the palaeo-rivers and documentation of multiple avulsion episodes, with consequences for the human habitation and use of the area through which these flowed.

The use of vegetation indices, however, did not offer any indication of the location of palaeo-rivers in the southeastern sector of the study area. This area is characterised by arid conditions and a reduced rainfall and, as NDVSI (Figure 4) clearly shows, seasonal variability does not produce significant changes in vegetation. Vegetation indices are, therefore, not considered a consistently reliable approach for the detection of palaeo-rivers in this area.

\subsection{Spectral Decomposition Techniques}

A total of 1920 kilometres of palaeo-channels have been detected through the use of spectral decomposition techniques of seasonal multi-temporal data. Not surprisingly, TCTs of the mean Monsoonal image composite values for Greenness and Wetness produced similar results for the northern area to those obtained with the application of vegetation indices. The RGB composite of the different bimensal EVIs was more efficient in detecting palaeo-rivers due to the higher temporal resolution of the data employed, which incorporated differences in seasonal rains. In contrast to the 
vegetation indices, TCT, however, excelled in the detection of palaeo-rivers in the southern sector of the study area where a large relic water course with several tributaries contributing to the Ghaggar-Hakra system was identified and its trace could be followed for more than $300 \mathrm{~km}$ (Figure 8). This feature was visible through its contrasting low value pixels in the fourth (where it was clearly discernible), sixth and only marginally in the second axis corresponding to greenness. The palaeo-river was noticeably more visible in the TCT of the dry months composite (Figure 8), slightly less in the TCT of the mean image of all available Landsat 5 imagery and scarcely visible in TCT of the monsoonal composite. This pattern of visibility indicates that, although seasonally variable, the visibility of this palaeo-river is not related to vegetation changes. This palaeo-channel might have been previously documented in part and with large inaccuracies by Yashpal et al. [22], who considered it a second old channel of the Yamuna River (Figure 7). Later, Rajani and Rajawat [37] identified its terminal sector as the Vedic Drishadvati. Recently, Mehdi et al. [39] again identified this palaeo-channel and reliably traced its course and those of several tributaries covering a total length of approximately $416 \mathrm{~km}$.

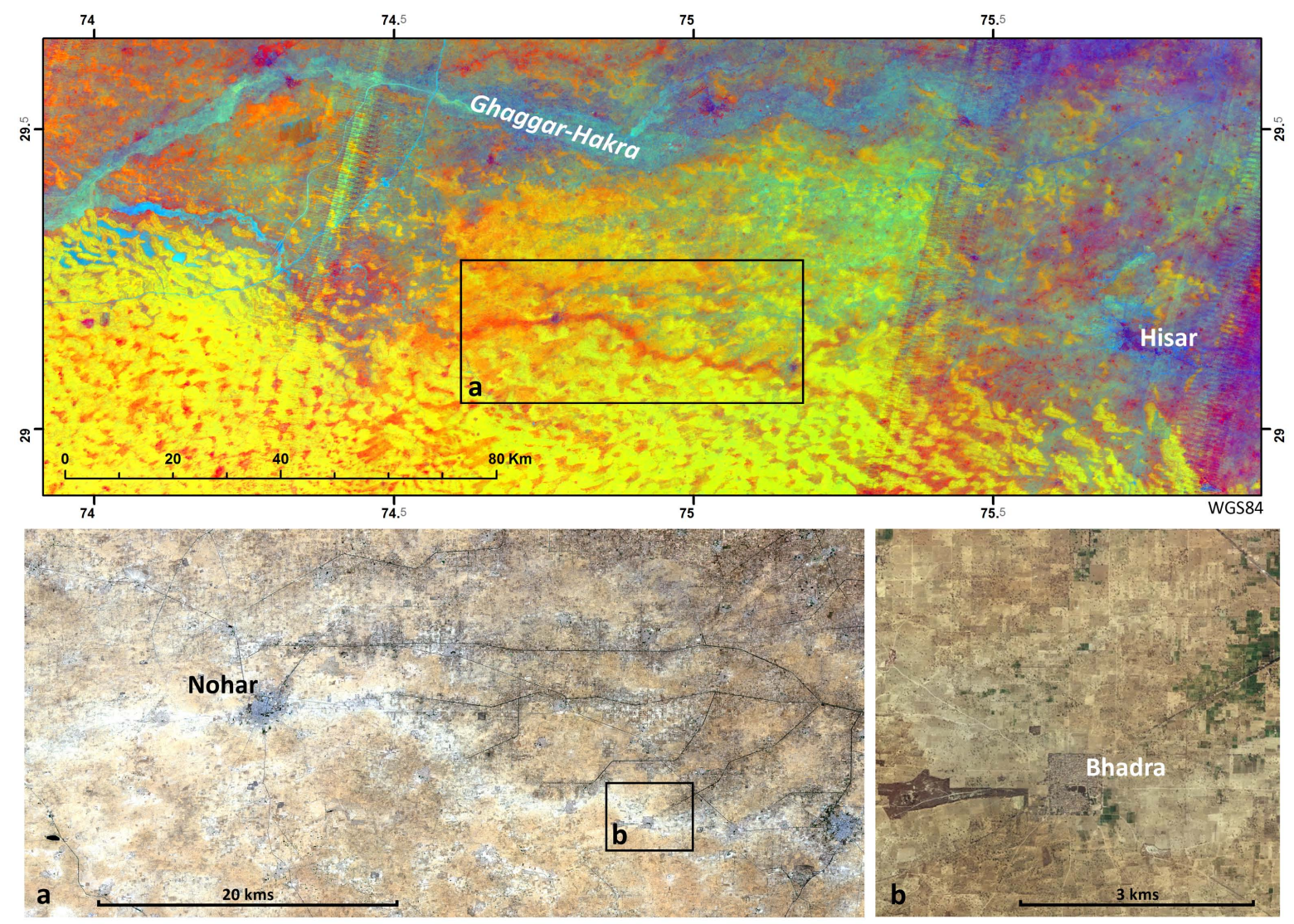

Figure 8. (Top) RGB (TCT axes 1, 4 and 2) composite of a multi-temporal seasonal mean of dry months Tasselled Cap Transformation. Note the higher albedo in the zoomed areas ((a,b) Sentinel 2 RGB natural colour composite of bands 4, 3 and 2) from Nohar to Bhadra.

Although slightly meandering, the course of this river does not show evidence of levees or aggradation, neither are these features present in the $30 \mathrm{~m} /$ cell SRTM data. Instead, its course is marked by a clear erosive channel, which corresponds to a higher slope than that documented from the northern plain. The orientation of this palaeo-river in conjunction to topographic data suggests that it might have been collecting water from different sources. While its northern section could have been sourced from the Yamuna River catchment, as suggested by Yashpal et al. [22], its southern tributary, which joins the northern channel in Bhadra (Figure 8b), appears to originate in the Aravalli range. This area of the Aravalli has an important component of carbonates. Dissolved carbonates could 
have been incorporated in the water and influenced the composition of the sediments transported by the river and deposited along its banks. Sediment rich in calcium carbonate has a clear colour, which could be responsible for the noticeably higher albedo of the fields along the palae-oriver course (Figure 8). The presence of carbonate, gypsiferous clay and strings of playa lakes are all considered residual elements of palaeo-channels [9] (p. 49). Although little geological coring has been done in this area, the presence of gypsum and carbonates is well documented in Karsandi palaeo-environmental record [52,53], $21 \mathrm{~km}$ south of this channel at Nohar. This particular composition of the channel's filling sediment could also explain the decreased visibility of the palaeo-river during the rainy season, as higher soil moisture would have reduced the contrast of carbonate-rich sediment. SRTM data also show how the southernmost tributary of this river is completely obliterated under the dunes marking the northeastern edge of the Thar Desert (Figure 8, dunes in bright yellow).

The southeastern sector of the study area between Hisar and the Yamuna (Figure 9), where NDVSI analysis produced average values for seasonal vegetation variability, also offered interesting results. Figure 9a shows a strong visibility of palaeo-rivers and channels in the southeastern extreme of the study area only during wet months, where an anastomosing river with multiple meander scars can be appreciated coming from the Yamuna bluff line. TCT of images acquired during the wet months shows similar detection capabilities to that of SMTVI (Figure 9b). In contrast, the complex network of palaeo-channels west of Hisar, and much closer to the Thar Desert edge, identified in Figure 9c area was only visible in the TCT produced from images taken during dry months. In many cases, particularly for the spectral decomposition techniques and the southeast sector, the alternation of multi-temporal seasonal means for dry and wet seasons provided complementary identifications as some palaeo-rivers or stretches of these were only visible during dry or wet seasons. The combination of seasonal images was also important because it allowed a clear differentiation between palaeo-rivers and irrigated fields, which formed linear and dendritic patterns (similar to those typical of palaeo-rivers) following water channels. Artificial channel-irrigated fields were particularly visible in the composites of dry seasons as their moisture content boosted their visibility with respect to their surrounding fields. Their identification was an important step to avoid the mapping of false-positive palaeo-rivers. This clearly exemplifies the importance of seasonality for the identification of palaeo-features in those areas where NDVSI shows average values for seasonal vegetation variability.

Seasonal PCA analysis of the mean values of L5 images produced similar, if less clear, results to those of the TCT. The northern network of palaeo-rivers was visible, although with much less detail than that obtained with the seasonal EVI analysis. This indicates the close relationship between the visibility of northern palaeo-rivers and long-term vegetation dynamics, which diffuses with the use of spectral decomposition techniques. The southern palaeo-river network (Figure 8) was only visible in the dry season PCA, where it displayed high values in principal components 3 and mostly 4 , where it was clearly identifiable. It seems therefore that seasonal PCA could provide a good approach to areas with less vegetation. In addition, the visibility of this palaeo-river network in the more marginal axes of TCT and PCA points to the inadequacy of the more conventional RS techniques usually applied in the detection of the ancient rivers in the Indus watershed. The success of the approach adopted by Mehdi et al. [39] in detecting a channel (Figure 9) joining the modern town of Hisar and the Indus city of Rakhigarhi is probably due to specific environmental conditions during the acquisition of the single Landsat 7 image from which these authors developed a PCA. Unfortunately, no information about this particular image was provided, and it thus not possible to evaluate their reconstruction.

For those areas with average and low NDVSI values, PCA seasonal analysis provided a complementary source of information to previous TCT and SMTVI data and was useful to increase the number of detected traces while reducing the number of false positives. 

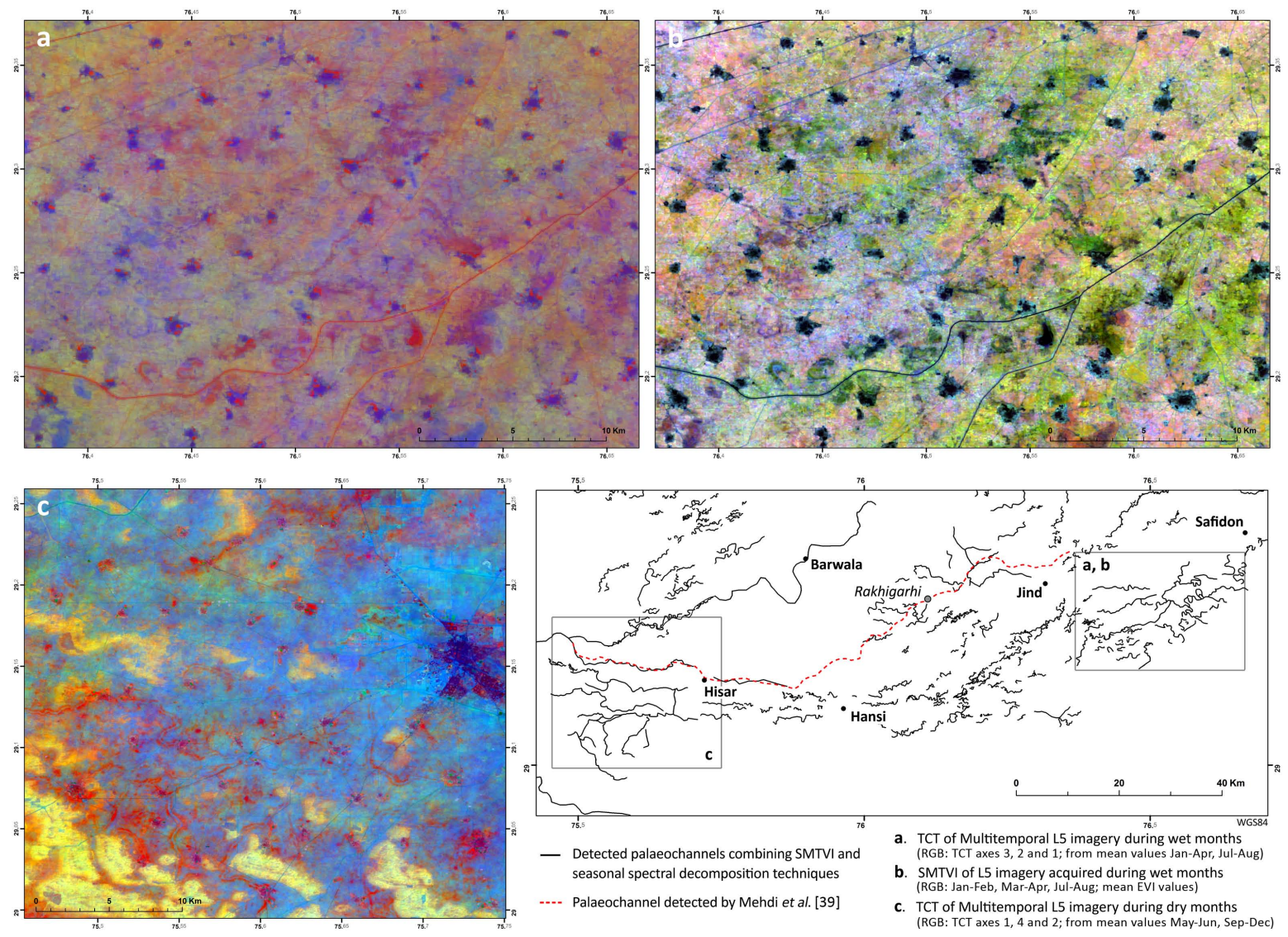

Figure 9. Comparison of visibility potential between different seasonal conditions and techniques illustrating the need to combine different approaches for the detection of palaeo-rivers.

\section{Discussion}

The analysis presented here demonstrates that the palaeo-rivers in the study area can take multiple forms as a result of topographic and sedimentologic factors in conjunction with discharge and hydrological parameters. Today, both smaller palaeo-channels and medium-sized past fluvial courses have been almost completely filled in and covered by a flattened and cultivated land surface. The largest palaeo-channels can also be preserved as subtle topographic features, which range from accumulated levee sediments and flattened filled up channels to carved channels. Sometimes these stages can all be related to different reaches of the same river as slope varies and varying amounts of water and sediment are incorporated.

The morphology, topography, and multiplicity of palaeo-rivers in the northern sector of the study area together with their spectral response to vegetation indicates that these were very active aggradational environments in which rivers carried a high suspended sediment fraction. Floods were a common feature of this landscape as suggested by the strong development of river levees. Flooding episodes in conjunction with the high bedload would have strongly contributed to the avulsion of many of these palaeo-rivers at one or several stages of their course. The agricultural use of these floodplains would have required good adaptation to flooding regimes and changing water conditions (including the specific location of water courses). The adoption of elevated settings for habitation and mobility are common past human responses to this type of variable environmental conditions $[10,54,55]$. It seems unlikely that settlements with a strictly agricultural economic orientation would have been situated on the proximal areas of these rivers' levees, not just because of the risk of flooding or river avulsion, but also of the lower agricultural productivity of these areas. The more distal areas of the levees, backswamps and floodplain would have offered better soils (more organic 
and with finer sediment) and a higher capacity for moisture retention. In this regard, SMTVI offers not just a way to detect palaeo-rivers but it can also be employed to explore agricultural potential.

The southern sector of the study area indicates an important influence of changing climatic conditions linked to the expansion of the Thar Desert and the progressive reduction and eventual cut off of water coming from the Aravalli range. The expansion of the Thar Desert toward the north must be accounted for, not only because of the eventual disappearance of this channel but also because of the possible presence of a more extended network of rivers coming from the Aravalli range and hidden beyond the capacity of current RS techniques under the expanding dunes of the Thar Desert. Singhvi and Kar's [56] review of the evidence for dune formation in the Thar Desert noted a west to east expansion during the mid-Holocene. This sector of the study area is located in the northeastern extreme of the Thar Desert with a similar rainfall pattern and latitude to that of Lake Didwana, which dried at around 4.2 kilo annum before present (ka BP) [57]. This increase in aridity, noted in the Didwana record could have reduced the amount of water available in these palaeo-rivers but, most importantly, marked the beginning of an important period of dune development in the north-eastern margin of the Thar desert, which might have been coincident with the Post-Urban or Late Harappan phase starting around 3.9 ka BP (ca. 1900 years Before Christ). Although, dune formation in the Thar desert is a long process spanning at least $200 \mathrm{ka} \mathrm{BP} \mathrm{[56],} \mathrm{some} \mathrm{recent} \mathrm{dating} \mathrm{of} \mathrm{dunes} \mathrm{from} \mathrm{the} \mathrm{northernmost} \mathrm{edge} \mathrm{of}$ the Thar desert, have suggested that dune deposits pre-date $4.9 \mathrm{ka} \mathrm{BP}$, though some are around 1500 years old ([27] (p. 4), [58-60]). Therefore, it seems logical to expect a long period of dune formation and interaction with rivers before the latter were finally erased. Interdunal areas at the desert edges are important reservoirs of surface and subsurface water during inter-monsoonal periods and have been long inhabited and exploited as highlighted by research at Gujarat [61]. The reconstruction of a large palaeo-channel in this area flanked by dunes and with a tributary emerging from a dune-dominated area (dunes are shown in yellow in Figure 8) might have been an important resource for the area's inhabitants even after dunes started to expand in this region.

The increase in aridity and the related weakening of the Summer Monsoon during the $4.2 \mathrm{ka}$ BP event, which may have been linked to the extension of the Thar Desert, might have also been a factor in the particular fluvial morphology detected in the northern sector of the study area. The natural increase in rivers sediment load has been employed as a proxy for dryer climatic conditions (e.g., [62]). In this regard, it is tempting to correlate the northern rivers' large ribbon shaped levees and avulsion episodes, closely related with high sediment loads, with a dryer period. If this were the case, the migration and avulsion towards the Sutlej catchment of the northern rivers and the subsidence of the southern network through the extension of dunes would have combined to significantly reduce the amount of water available to the Ghaggar-Hakra. However, the current lack of chronological data on the periods of activity of the detected rivers prevents us from investigating such hypotheses yet.

The data provided by these analyses are also important in contextualising previous studies in which palaeo-rivers have been dated using the distribution of known archaeological sites. Notwithstanding the positional accuracy of these locations (see $[10,63,64])$, which would severely hamper their use for validation purposes, the results for the northern sector of the study area (Figure 3) suggest that proximity to the river might not be a good indication of contemporaneity as the fields close to the river channel might not have been the most productive in agricultural terms. Sites with an agricultural orientation might have preferred to occupy elevations above flooding level in the finer sediment accumulation area. Flooding events and changing river courses could also have had an important effect in the preservation of archaeological sites eroding and burying those that were located in the path of new courses or in their sediment accumulation areas.

In addition to these factors, the scale at which these correlations between specific palaeo-channels and settlement locations have usually been published (e.g., [30] (pp. 359-387), [31] (Figure 4.2)]) do not allow the accurate correlation between the two elements. The use of large area (small scale in a geographic sense) site distribution maps for these correlations results in a visual association between the shape of the palaeo-river and the line formed by the grouping of sites, but at these scales the 
sites could be aligned to a number of palaeo-channels given the number of rivers and the parallel morphology of the drainage in the Sutlej-Yamuna interfluve revealed here. This analysis thus suggests that at these scales it is not possible to co-relate lineal distribution of archaeological sites to any particular palaeo-river that we have documented. The results from previous studies reconstructing the chronology of the hydrological system using the position of archaeological sites and vice versa (e.g., [24,25], [30] (pp. 359-384), and [31]) are, therefore, considered unreliable.

The adoption of a multi-technique seasonal approach (SMTVI, Seasonal TCT and seasonal PCA) has enabled us to avoid false positive identifications while achieving a high degree of accuracy and multiplying the number of known palaeo-rivers as demonstrated by the comparison with previous studies carried out in the study area. However, since the current knowledge of site distribution patterns and the nature of their relationship to ancient river courses are inaccurate at best quantification of error, which has usually employed the distribution of known archaeological sites, is difficult to measure at this stage. Historic map analysis and fieldwork aimed at the verification of site locations and palaeo-rivers is currently being developed and will be the object of future publications.

\section{Conclusions}

While previous remote sensing approaches using single images acquired at the moment of maximum visibility of a particular palaeo-river can offer excellent visibility of specific features, they will not necessarily be (and often simply will not) be able to reveal other aspects of a hydrologic network. Of course, these approaches would be unviable for the reconstruction of the entirety of a complex network, which in this case includes a very large area that can only be covered by hundreds of images.

For this study, more than $8000 \mathrm{~km}$ of palaeo-rivers have been mapped and, although some of those have been already identified by previous studies, our results show that previous approaches to the study of the river systems of the Yamuna-Sutlej Interfluve need major reconsideration. This study thus has important implications for perceived spatial correlations between the distribution of archaeological sites and the course of particular palaeo-rivers. RS visibility patterns have provided important insights into the fluvial geomorphology, water distribution and depositional history of the study area, which, in turn provide significant new data to model the human occupation of these spaces. Given the complexity of the hydrological system, the variety in the climatic and weather system of this region, and the diversity of ways that ancient populations are likely to have obtained water, it is unwise to use the date of occupation at specific settlements to date when specific channels carried water. It is essential to date the different palaeo-courses independently to properly reconstruct the evolution of hydrological networks over long periods. The chronologically consistent reconstruction of this palaeo-river network would allow the testing of different hypothetical scenarios of water availability through the use of network analysis in combination to hydrological analysis. Future work within the TwoRains project will concentrate on: (1) gathering of accurate palaeo-environmental and cultural data and absolute dating evidence to date the activity of the different palaeo-rivers detected; and (2) creating a database of well-dated and accurately positioned archaeological sites that could allow the statistical inference of relationships between distribution of sites and palaeo-rivers and their potential flooding areas.

The important increase in the detected palaeo-rivers achieved by this study can be attributed to the use of multi-temporal data filtered by season. Previous studies using single data sources or a selection with scarce temporal variability have failed to factor the multiple environmental and cultural (cultivation patterns) conditions that determine the visibility of palaeo-rivers. The use of a seasonal multi-temporal approach has allowed us to overcome seasonal visibility problems associated with soil moisture and vegetation health, yearly changes in cultivation patterns and long-term changes in the selection of cultivated crops. In this regard, this study clearly illustrates the need to employ a multi-temporal seasonal approach and a combination of data treatment techniques. 
Our results prove that the factors influencing water availability along the Ghaggar-Hakra basin are much more complex than previously thought. The traces of palaeo-rivers that have been identified cover the entirety of the landscape in the northern sector forming an almost continuous parallel pattern, which points to the changing nature of these channels and the likelihood that floods and river avulsions have been a relative common occurrence. The waters feeding the various palaeo-rivers originated from glacier-fed sources, such as water supplying the various palaeo-rivers related to the Sutlej, which appear to include the main Ghaggar-Hakra channel, as well as monsoonal rain which is likely to have contributed to both perennial and ephemeral rivers (see $[10,27,65])$. The geographic source of watercourses ranges from the Himalayas to the Aravalli mountains, and seasonal rain patterns and discharge across this zone are very different. All these factors join to create an extremely complex picture in which water availability and location is dependent upon a multiplicity of factors and difficult to predict in the long term.

The methodology outlined in this paper and its associated code in combination with the resources made available through Google Earth Engine ${ }^{\odot}[66]$ can easily be applied to other areas with similar problematics. Given the importance of water sources and water availability for the flourishing, expansion and environmental resilience of ancient civilisations, the development of new methods for the reconstruction of ancient waterscapes is of great importance. Our results highlight the enormous potential of satellite-based Big Data analysis for archaeological research, which, with notable exceptions (e.g., [67]), are still underexploited.

Supplementary Materials: Supplementary Materials: The following are available online at www.mdpi.com/ 2072-4292/9/7/735/s1.

Acknowledgments: The research presented in this paper has been carried out as part of the TwoRains project (http://www.arch.cam.ac.uk/research/projects/two-rains), which is a multi-disciplinary investigation of climate change and the Indus civilization in northwest India. TwoRains is funded by a Horizon 2020 European Research Council (ERC) Consolidator Grant (H2020, 648609), and is based in the McDonald Institute for Archaeological Research at the University of Cambridge. TwoRains is being carried out in collaboration with Prof. Ravindra Nath Singh and the Department of AIHC and Archaeology at Banaras Hindu University, and the authors would like to thank Prof. Singh, BHU and the members of the Land, Water and Settlement project (http:/ /www.arch.cam.ac.uk / research/projects/land-water-settlement), whose work has laid the foundations for the work now being carried out by the TwoRains project. The authors would also like to thank Alexandra Livarda for her help with references and her valuable observations and the five anonymous reviewers who read the paper for their positive comments and useful suggestions.

Author Contributions: H.A.O. developed the methods, executed the analysis, and made the lead contribution to the writing. C.A.P. designed the broad research strategy for the work and made a substantial contribution to the writing.

Conflicts of Interest: The authors declare no conflict of interest.

\section{References}

1. Bisson, M.; Piccinini, S.; Zanchetta, G. A multidisciplinary GIS-based approach for mapping paleoriver migration: A case study of the Serchio River (Lucca Alluvial Plain, Tuscany). GISci. Remote Sens. 2011, 48, 566-582. [CrossRef]

2. Blumberg, D.G.; Neta, T.; Margalit, N.; Lazar, M.; Freilikher, V. Mapping exposed and buried drainage systems using remote sensing in the Negev desert, Israel. Geomorphology 2004, 61, 239-250. [CrossRef]

3. McCauely, J.F.; Blom, R.; Breed, C.S.; Elachi, C.; Grolier, M.J.; Haynes, C.V.; Issawi, B.; Schaber, G.G. Subsurface valleys and geoarchaeology of the Eastern Sahara revealed by shuttle radar. Science 1982, 218, 1004-1020. [CrossRef] [PubMed]

4. Orengo, H.A.; Ejarque, A.; Albiach, R. Water management and land-use practices from the Iron-Age to the Roman period in Eastern Iberia. J. Archaeol. Sci. 2014, 49, 265-275. [CrossRef]

5. Rossetti, D.F.; Góes, A.M. Late quaternary drainage dynamics in northern Brazil based on the study of a large paleochannel from southwestern Marajó Island. An. Acad. Bras. Cienc. 2008, 80, 579-593. [CrossRef] [PubMed]

6. Tapley, I.J. The reconstruction of palaeodrainage and regional geologic structures in Australia's Canning and Officer Basins using NOAA-AVHRR satellite imagery. Earth-Sci. Rev. 1988, 25, 409-425. [CrossRef] 
7. Walstra, J.; Heyvaert, V.M.A.; Verkinderen, P. 2009 Remote sensing for the study of fluvial landscapes in Lower Khuzestan, SW Iran. In Proceedings of the Remote Sensing and Photogrammetry Society Conference, Leicester, UK, 8-11 September 2009.

8. Yang, X.; Damen, M.C.J.; van Zuidam, R.A. Satellite remote sensing and GIS for the analysis of channel migration changes in the active Yellow River Delta, China. Int. J. Appl. Earth Obs. 1999, 1, 146-157. [CrossRef]

9. Hou, B.; Mauger, A. How well does remote sensing aid palaeochannel identification?-An example from the Harris Greenstone Belt. MESA J. 2005, 38, 46-52.

10. Petrie, C.A.; Singh, R.N.; Bates, J.; Dixit, Y.; French, C.A.I.; Hodell, D.; Jones, P.J.; Lancelotti, C.; Lynam, F.; Neogi, S.; et al. Adaptation to variable environments, resilience to climate change: Investigating Land, Water and Settlement in northwest India. Curr. Anthropol. 2017, 58, 1-30. [CrossRef]

11. Marshall, J. Mohenjo-Daro and the Indus Civilisation; Arthur Probsthain: London, UK, 1931.

12. Wright, R.P. The Ancient Indus. Urbanism, Economy and Society; Cambridge University Press: New York, NY, USA, 2010.

13. Oldham, C.F. Notes on the lost river of the Indian desert. Calcutta Rev. 1874, 59, 1-29.

14. Oldham, C.F. The Sarasvati and the lost river of the Indian desert. J. R. Asiat. Soc. 1893, 34, 49-76.

15. Oldham, R.D. On probable changes in the geography of the Punjab and its rivers: An historicogeographical study. J. Asiat. Soc. Bengal 1886, 55, 322-343.

16. Stein, M.A. A survey of ancient sites along the lost Saraswati river. Geogr. J. 1942, 99, 173-182. [CrossRef]

17. Ghose, A. The Rajputana Desert-Its archaeological aspect. Bull. Natl. Inst. Sci. India 1952, I, $37-42$.

18. Lambrick, H.T. Sind: A General Introduction; History of Sind Series 1; Sindhi Abadi Board: Hyderabad, India, 1964.

19. Lambrick, H.T. The Indus flood-plain and the "Indus" civilization. Geogr. J. 1967, 133, 483-494. [CrossRef]

20. Raikes, R. Kalibangan: Death from natural causes. Antiquity 1968, 42, 286-291. [CrossRef]

21. Rajaram, N.S. Sarasvati River and the Vedic Civilization: History, Science, and Politics; Aditya Prakashan: New Delhi, India, 2006.

22. Yashpal, S.B.; Sood, R.K.; Agarwal, D.P. Remote sensing of the 'Lost' Sarasvati River. P Indian AS-Earth 1980, 89, 317-331.

23. Mughal, M.R. Ancient Cholistan: Archaeology and Architecture; Ferozsons: Lahore, Pakistan, 1997.

24. Lal, B.B. The Sarasvati Flows on: The Continuity of Indian Culture; Aryan Books International: New Delhi, India, 2002.

25. Valdiya, K.S. Saraswati: The River that Disappeared; Indian Space Research Organisation and Universities Press: Hyderabad, India, 2002.

26. Srivastava, G.S.; Singh, I.B.; Kulshrestha, A.K. Late quaternary geomorphic evolution of Yamuna-Sutlej Interfluve. Significance of terminal fan. J. Indian Soc. Remote Sens. 2006, 34, 123-130. [CrossRef]

27. Giosan, L.; Clift, P.D.; Macklin, M.G.; Fuller, D.Q.; Constantinescu, S.; Durcan, J.A.; Stevens, T.; Duller, G.A.T.; Tabrez, A.R.; Gangal, K.; et al. Fluvial landscapes of the Harappan civilization. Proc. Natl. Acad. Sci. USA 2012, 109, E1688-E1694. [CrossRef] [PubMed]

28. Singh, R.N.; Petrie, C.A.; Pawar, V.; Pandey, A.K.; Neogi, S.; Singh, M.; Singh, A.K.; Parikh, D.; Lancelotti, C. Changing patterns of settlement in the rise and fall of Harappan urbanism: Preliminary report on the Rakhigarhi Hinterland Survey 2009. Man Environ. 2010, 35, 37-53.

29. Singh, R.N.; Petrie, C.A.; Pawar, V.; Pandey, A.K.; Parikh, D. New insights into settlement along the Ghaggar and its hinterland: A preliminary report on the Ghaggar Hinterland Survey 2010. Man Environ. 2011, 36, 89-106.

30. Possehl, G.L. Indus Age: The Beginnings; University of Pennsylvania Press: Philadelphia, Penn, USA, 1999.

31. Danino, M. The Lost River: On the Trail of the Saraswati; Penguin: Delhi, India, 2010.

32. Ramasamy, S.M.; Bakliwal, P.C.; Verma, R.P. Remote sensing and river migration in Western India. Int. J. Remote Sens. 1991, 12, 2597-2609. [CrossRef]

33. Sharma, D.C.; Kalra, N.K.; Srivastava, A.; Singh, R.B. An appraisal of space technology to identify the palaeochannels of river Saraswati in Anupgarh, Pilibanga and parts of Ganganagar and Hanumangarh districts. In Geological Evolution of Northwestern India; Paliwal, B.S., Ed.; Scientific Publishers: Jodhpur, India, 1999; pp. 260-270.

34. Gupta, A.K.; Sharma, J.R.; Sreenivasan, G.; Srivastava, K.S. New findings on the course of river Sarasvati. J. Indian Soc. Remote Sens. 2004, 32, 1-24. [CrossRef] 
35. Gupta, A.K.; Sharma, J.R.; Sreenivasan, G. Using satellite imagery to reveal the course of an extinct river below the Thar Desert in the Indo-Pak region. Int. J. Remote Sens. 2011, 32, 5197-5216. [CrossRef]

36. Bhadra, B.K.; Gupta, A.K.; Sharma, J.R. Saraswati Nadi in Haryana and its linkage with the Vedic Saraswati River - Integrated study based on satellite images and ground Based information. J. Geol. Soc. India 2009, 73, 273-288. [CrossRef]

37. Rajani, M.B.; Rajawat, A.S. Potential of satellite based sensors for studying distribution of archaeological sites along palaeo channels: Harappan sites a case study. J. Archaeol. Sci. 2011, 38, 2010-2016. [CrossRef]

38. Wright, R.P.; Hritz, C. Satellite remote sensing imagery: New evidence for site distributions and ecologies in the upper Indus. In South Asian Archaeology 2007. Proceedings of the 19th International Conference of the European Association of South Asian Archaeology. Ravenna, Italy, 2-6 July 2007. Volume I Prehistoric Periods; Frenez, D., Tosi, M., Eds.; Archaeopress: Oxford, UK, 2013; pp. 315-321.

39. Mehdi, S.M.; Pant, N.C.; Saini, H.S.; Mujtaba, S.A.I.; Pande, P. Identification of palaeochannel configuration in the Saraswati River basin in parts of Haryana and Rajasthan, India, through digital remote sensing and GIS. Episodes 2016, 39, 29-38. [CrossRef]

40. van Dijk, W.M.; Densmore, A.L.; Singh, A.; Gupta, S.; Sinha, R.; Mason, P.J.; Joshi, S.K.; Nayak, N.; Kumar, M.; Shekhar, S.; et al. Linking the morphology of fluvial fan systems to aquifer stratigraphy in the Sutlej-Yamuna plain of northwest India. J. Geophys. Res-Earth 2016, 121, 201-222. [CrossRef]

41. Bakliwal, P.C.; Sharma, S.B. On the migration of the River Yamuna. Geol. Soc. India 1980, 21, 461-463.

42. Huete, A.; Didan, K.; Miura, T.; Rodriguez, E.P.; Gao, X.; Ferreira, L.G. Overview of the radiometric and biophysical performance of the MODIS vegetation indices. Remote Sens. Environ. 2002, 83, 195-213. [CrossRef]

43. Gao, B. NDWI-A normalized difference water index for remote sensing of vegetation liquid water from space. Remote Sens. Environ. 1996, 58, 257-266. [CrossRef]

44. Chander, G.; Markham, B.L.; Helder, D.L. Summary of current radiometric calibration coefficients for Landsat MSS, TM, ETM+, and EO-1 ALI sensors. Remote Sens. Environ. 2009, 113, 893-903. [CrossRef]

45. Zhu, Z.; Wang, S.; Woodcock, C.E. Improvement and expansion of the Fmask algorithm: Cloud, cloud shadow, and snow detection for Landsats 4-7, 8, and Sentinel 2 images. Remote Sens. Environ. 2015, 159, 269-277. [CrossRef]

46. Kauth, R.J.; Thomas, G.S. The tasselled cap-A graphic description of the spectral-temporal development of agricultural crops as seen by LANDSAT. In Proceedings of the Symposium on Machine Processing of Remotely Sensed Data, Purdue University of West Lafayette, Indiana, 1976; Institute of Electrical and Electronics Engineers: New York, NY, USA, 1976; pp. 4B-41-4B-51.

47. Crist, E.P.; Cicone, R.C. Application of the tasselled cap concept to simulated thematic mapper data. Photogramm Eng. Remote Sens. 1984, 50, 343-352.

48. Crist, E.P.; Cicone, R.C. A physically-based transformation of thematic mapper data-The TM tasselled cap. IEEE Trans. Geosci. Remote 1984, 22, 256-263. [CrossRef]

49. Hudson, P.F.; Heitmuller, F.T. Local- and watershed-scale controls on the spatial variability of natural levee deposits in a large fine-grained floodplain: Lower Pánuco Basin, Mexico. Geomorphology 2003, 56, 255-269. [CrossRef]

50. Cazanacli, D.; Smith, N.D. A study of morphology and texture of natural levees - Cumberland Marshes, Saskatchewan, Canada. Geomorphology 1998, 25, 43-55. [CrossRef]

51. Brierley, G.J.; Ferguson, R.J.; Woolfe, K.J. What is a fluvial levee? Sediment Geol. 1997, 114, 1-9. [CrossRef]

52. Saini, H.S.; Tandon, S.K.; Mujtaba, S.A.I.; Pant, N.C.; Khorana, R.K. Reconstruction of buried channel-Floodplain systems of the northwestern Haryana Plains and their relation to the 'Vedic' Saraswati. Curr. Sci. India 2009, 97, 1634-1643.

53. Dixit, Y.; Hodell, D.A.; Giesche, A.; Gázquez, F.; Tandon, S.K.; Saini, H.S.; Skinner, L.; Mujtaba, S.A.I.; Singh, R.N.; Petrie, C.A. Intensified Indian summer monsoon and the urbanization of the Indus Civilization in northwest India. Nat. Commun. 2017. in preparation.

54. Neogi, S. Geoarchaeological Investigations of Indus Settlements in the Plains of Northwestern India. Ph.D. Thesis, University of Cambridge, Cambridge, UK, 2013.

55. Neogi, S.; French, C.A.I.; Pawar, V.; Singh, R.N.; Petrie, C.A. Geoarchaeological insights into the location of Indus settlements in the plains of northwest India. Quat. Res. 2017, in press. 
56. Singhvi, A.K.; Kar, A. The aeolian sedimentation record of the Thar Desert. J. Earth Syst. Sci. 2004, 113, 371-402. [CrossRef]

57. Singh, G.; Wasson, R.J.; Agrawal, D.P. Vegetational and seasonal climatic changes since the last full glacial in the Thar Desert, northwestern India. Rev. Palaeobot. Palyno. 1990, 64, 351-358. [CrossRef]

58. Shitaoka, Y.; Maemoku, H.; Nagatomo, T. Quartz OSL dating of sand dunes in Ghaggar Basin, 578 northwestern India. Geochronometria 2012, 39, 221-226. [CrossRef]

59. Maemoku, H.; Shitaoka, Y.; Natomo, T.; Yagi, H. Geomorphological constraints on the Ghaggar River Regime during the Mature Harappan period. In Climates, Landscapes, and Civilizations; Giosan, L., Fuller, D.Q., Nicoll, K., Flad, R.K., Clift, P.D., Eds.; American Geophysical Union, Geophysical Monograph 198: Washington, DC, USA, 2012; pp. 97-106.

60. Durcan, J.A.; Thomas, D.S.G.; Gupta, S.; Pawar, V.; Singh, R.N.; Petrie, C.A. Holocene landscape dynamics in the Ghaggar-Hakra palaeochannel region at the northern edge of the Thar Desert, northwest India. Quat. Int. 2016, in press.

61. Conesa, F.C.; Devanthéry, N.; Balbo, A.L.; Madella, M.; Moserrat, O. Use of satellite SAR for understanding long-term human occupation dynamics in the monsoonal semi-arid plains of North Gujarat, India. Remote Sens. 2014, 6, 11420-11443. [CrossRef]

62. Langford-Smith, T. Riverine plains geochronology. Aust. J. Sci. 1962, 25, 96-97.

63. Singh, R.N.; Petrie, C.A.; French, C.A.I.; Goudie, A.S.; Gupta, S.; Tewari, R.; Singh, A.K.; Sihna, R.; Srivastava, R.; Yadav, S.; et al. Settlements in context: Reconnaissance in western Uttar Pradesh and Haryana. Man Environ. 2008, 33, 71-87.

64. Green, A.S.; Petrie, C.A. Landscapes of urbanisation and de-urbanization: Integrating site location datasets from northwest India to investigate changes in the Indus Civilization's settlement distribution. J.Field Arch. 2017. in preparation.

65. Clift, P.D.; Carter, A.; Giosan, L.; Durcan, J.; Duller, G.A.T.; Macklin, M.G.; Alizai, A.; Tabrez, A.R.; Danish, M.; VanLaningham, S.; et al. U-Pb zircon dating evidence for a pleistocene Sarasvati River and capture of the Yamuna River. Geology 2012, 40, 211-214. [CrossRef]

66. Google Earth Engine Team. Google Earth Engine: A Planetary-Scale Geo-Spatial Analysis Platform. Available online: https:/ / earthengine.google.com (accessed on 6 February 2017).

67. Agapiou, A. Remote sensing heritage in a petabyte-scale: Satellite data and heritage Earth Engine $(\mathrm{C}$ applications. Int. J. Digit. Earth 2017, 10, 85-102. [CrossRef] 